Article

\title{
Synthesis and Characterization of Flower-like Carbon-encapsulated Fe-C Nanoparticles for Application as Adsorbing Material
}

\author{
Lixin Zhao ${ }^{1}$, Xibin Dai ${ }^{1}$, Baoe Li ${ }^{1}$, Hongshui Wang ${ }^{1}$, Haipeng $\mathrm{Li}^{1,2, *}$ and Chunyong Liang ${ }^{1,2, *}$ \\ 1 School of Materials Science and Engineering, Hebei University of Technology, Tianjin 300130, China; \\ zhaolixin0410@163.com (L.Z.); dainothingpossible@163.com (X.D.); libaoe@hotmail.com (B.L.); \\ kingflood@163.com (H.W.) \\ 2 Research Institute for Energy Equipment Materials, Hebei University of Technology, Tianjin 300130, China \\ * Correspondence: 2002026@hebut.edu.cn (H.L.); liangchunyong@hebut.edu.cn (C.L.)
}

Received: 20 January 2019; Accepted: 7 March 2019; Published: 12 March 2019

check for updates

\begin{abstract}
Carbon-encapsulated Fe-C (Fe-C@C) nanoparticles with a divergently flower-like morphology were successfully synthesized for application as an adsorbing material by using freeze-drying and chemical vapor deposition (CVD) methods. The Fe metallic source was first loaded onto a sodium chloride $(\mathrm{NaCl})$ supporter via freeze-drying to obtain the $\mathrm{Fe} / \mathrm{NaCl}$ composite powder. Then, Fe-C@C nanoparticles were synthesized in the temperature range of $300-450{ }^{\circ} \mathrm{C}$ via $\mathrm{CVD}$ of acetylene in the $\mathrm{Fe} / \mathrm{NaCl}$ composite powder using Fe nanoparticles as catalysts and $\mathrm{NaCl}$ as supporters. Because the $\mathrm{NaCl}$ supporter is water-soluble, the synthesized Fe-C@C nanoparticles were easy to purify, and a high purity was obtained by simple washing and centrifugation. The optimal Fe-C@C nanoparticles, synthesized at $400{ }^{\circ} \mathrm{C}$, possessed a unique divergently flower-like structure and a high specific surface area of $169.4 \mathrm{~m}^{2} / \mathrm{g}$ that can provide more adsorption sites for contaminants. Adsorption experiments showed that the flower-like Fe-C@C adsorbent exhibited high adsorption capacity $(90.14 \mathrm{mg} / \mathrm{g})$ and fast removal of methylene blue (MB). Moreover, the magnetic properties of the nanoparticles, with saturation magnetization of $36.544 \mathrm{emu} / \mathrm{g}$, facilitated their magnetic separation from wastewater. Therefore, the novel flower-like Fe-C@C nanoparticles with integrated adsorptive and magnetic properties have the potential to be an effective adsorbent in dye wastewater treatment.
\end{abstract}

Keywords: carbon-encapsulated magnetic nanoparticles; chemical vapor deposition; magnetic property; adsorptive property

\section{Introduction}

In recent years, organic dyes have been widely used in the industrial production of paper, textiles, printing, plastics, and other industries [1,2]. Most organic dyes are toxic, even carcinogenic, and are also stable and resistant to photolysis and biodegradation [3,4]. Thus, the development of a convenient and effective technology for treating wastewater contaminated with organic dyes is important. Compared with the decomposition of organic pollutants in water, it is more efficient to separate pollutants via adsorption [5]. Because of their low cost, resistance to acid and alkali corrosion, high specific surface area, and enhanced adsorption capacity, carbon materials have been widely used as adsorbents in the treatment of dye wastewater [6]. However, carbonaceous adsorbents are hard to separate from the dye wastewater after the adsorption process, especially nanoscale adsorbents [7]. A new type of adsorbent, carbon-encapsulated magnetic nanoparticles (CEMNPs), can solve this problem by virtue of its unique core-shell structure, good stability and compatibility, and especially excellent magnetic properties [8-10]. However, some problems still remain with CEMNP adsorbents, including the 
incomplete carbon-encapsulated shells that cause their stability and magnetic properties to degrade under harsh conditions, and a low specific surface area that results in poor adsorption capacity and rate. In addition, obtaining highly purified CEMNPs is still a challenge due to the limitations of the synthesis process.

To solve these problems, several improved solid-state synthesis methods, such as template methods and carbothermal reduction methods [11-13], have been used to synthesize CEMNPs. Unfortunately, these methods inevitably produce large amounts of amorphous carbon as a by-product, and some incompletely coated particles still exist. Pulsed laser irradiation can be used to form complete carbon encapsulation layers of CEMNPs [14], but the yield of this process is relatively low and the particle size is difficult to control. In contrast, the particle size of CEMNPs synthesized using spray pyrolysis is relatively uniform [15]. However, agglomeration of CEMNPs at high temperatures may cause a decrease in specific surface area and adsorption activity. Among the methods for synthesizing CEMNPs, chemical vapor deposition (CVD) has received increased attention because of its relatively low cost, potentially high yield, simplicity, and the availability of raw materials [16,17]. However, ceramic materials (e.g., $\mathrm{Al}_{2} \mathrm{O}_{3}, \mathrm{SiC}$, and $\mathrm{MgO}$ ) are often employed as the catalytic supporter in synthesizing CEMNPs using CVD [18,19]. These ceramic supporters are difficult to completely remove from the final product, which affects the purity, and thus degrades the performance of the CEMNPs. Recently, we proposed a novel approach about the synthesis of high-purity carbon-encapsulated cobalt (Co@C) nanoparticles using the CVD method [20]. However, there are still some disadvantages that limit the application of $\mathrm{Co@C}$ as an adsorbent, including low saturation magnetization, which makes it difficult to separate the adsorbent from the wastewater. In addition, Co has heavy-metal toxicity and is a potential threat to human health if used in water treatment processes [21]. Therefore, the fabrication of nontoxic high-purity CEMNPs with excellent adsorptive and magnetic properties continues to be a challenge.

In this paper, we present our proposed novel approach to synthesize carbon-encapsulated Fe-C (Fe-C@C) nanoparticles using CVD combined with freeze-drying. Basically, ferric citrate $\left(\mathrm{FeC}_{6} \mathrm{H}_{5} \mathrm{O}_{7}\right)$ is loaded onto the surface of sodium chloride $(\mathrm{NaCl})$ by freeze-drying to obtain the $\mathrm{Fe}_{2} \mathrm{O}_{3} / \mathrm{NaCl}$ catalyst precursor after calcination, which is then used to synthesize Fe-C@C nanoparticles supported on $\mathrm{NaCl}$ via CVD method. Because $\mathrm{NaCl}$ is water-soluble, the $\mathrm{NaCl}$ supporter can be removed by simple washing with water and centrifugation to obtain high-purity Fe-C@C nanoparticles. The synthesized core-shell Fe-C@C nanoparticles have a divergently flower-like morphology and a high specific surface area, which provide more adsorption sites for contaminants. Therefore, they exhibit a high adsorption capacity and fast removal of methylene blue (MB). In addition, because the Fe-C@C nanoparticles have superior magnetic properties, it is easy to separate them from wastewater. Thus, the novel adsorbent Fe-C@C nanoparticles, with their excellent adsorptive and magnetic properties, have great potential for use in the field of water treatment.

\section{Materials and Methods}

\subsection{Materials}

All chemicals were commercially available and analytical grade unless otherwise stated. $\mathrm{FeC}_{6} \mathrm{H}_{5} \mathrm{O}_{7} \cdot 5 \mathrm{H}_{2} \mathrm{O}$ (99.5\% purity) and $\mathrm{NaCl}$ (99.5\% purity) were obtained from Tianjin Guangfu Fine Chemical Research Institute (Tianjin, China). High-purity argon (Ar, 99.999\% purity), high-purity hydrogen $\left(\mathrm{H}_{2}, 99.999 \%\right.$ purity), and acetylene $\left(\mathrm{C}_{2} \mathrm{H}_{2}, 99.9 \%\right.$ purity) were purchased from Tianjin Liufang Industrial Gas Co., Ltd. (Tianjin, China). $\mathrm{MB}\left(\mathrm{C}_{16} \mathrm{H}_{18} \mathrm{ClN}_{3} \mathrm{~S} \cdot 3 \mathrm{H}_{2} \mathrm{O}, 98.5 \%\right.$ purity), an organic dye, was purchased from Tianjin Benchmark Chemical Reagent Co., Ltd. (Tianjin, China).

\subsection{Synthesis of Fe-C@C Nanoparticles}

Figure 1 presents the process used in this study to fabricate Fe-C@C nanoparticles. Fe and $\mathrm{C}_{2} \mathrm{H}_{2}$ were used as graphitization catalyst and carbon source, respectively. The $\mathrm{Fe}_{2} \mathrm{O}_{3} / \mathrm{NaCl}$ catalyst 
precursor was prepared via freeze-drying and calcination using $\mathrm{FeC}_{6} \mathrm{H}_{5} \mathrm{O}_{7} \cdot 5 \mathrm{H}_{2} \mathrm{O}$ and $\mathrm{NaCl}$ as raw materials. In a typical procedure, $\mathrm{NaCl}$ was dissolved in deionized water with continuous stirring for 30 min to form a $\mathrm{NaCl}$ aqueous solution with a mass concentration of $5.97 \mathrm{wt} \%$. A FeC $\mathrm{H}_{5} \mathrm{O}_{7} \cdot 5 \mathrm{H}_{2} \mathrm{O}$ aqueous solution with a mass concentration of $1.96 \mathrm{wt} \%$ was then added into the $\mathrm{NaCl}$ aqueous solution and stirred for $3 \mathrm{~h}$ at $60^{\circ} \mathrm{C}$ to obtain a uniform mixture with a Fe: $\mathrm{NaCl}$ weight ratio of 1:19 (Figure 1a). The mixed solution was transferred to several centrifuge tubes for freeze-drying at $-40{ }^{\circ} \mathrm{C}$ for $36 \mathrm{~h}$ (Figure $1 \mathrm{~b}$ ) to obtain the yellow mixture of $\mathrm{FeC}_{6} \mathrm{H}_{5} \mathrm{O}_{7} / \mathrm{NaCl}$ (Figure 1c). The mixture was ground in an agate mortar to a fine powder and then calcined in an air atmosphere at $500{ }^{\circ} \mathrm{C}$ for $1 \mathrm{~h}$ to obtain the $\mathrm{Fe}_{2} \mathrm{O}_{3} / \mathrm{NaCl}$ catalyst precursor (Figure 1d). The catalyst precursor was then loaded into an alumina boat, which was placed in the flat-temperature zone of a tube furnace and heated to $600{ }^{\circ} \mathrm{C}$ with Ar protection $(100 \mathrm{~mL} / \mathrm{min})$ at $10{ }^{\circ} \mathrm{C} / \mathrm{min}$. When the temperature reached $600{ }^{\circ} \mathrm{C}$, Ar flow was stopped and $\mathrm{H}_{2}\left(100 \mathrm{~mL} / \mathrm{min}\right.$, Figure 1eI) was introduced into the furnace for $1 \mathrm{~h}$ to reduce $\mathrm{Fe}_{2} \mathrm{O}_{3}$, after which the furnace was cooled to one of four synthesis temperatures $\left(300,350,400\right.$, and $\left.450{ }^{\circ} \mathrm{C}\right)$. When a synthesis temperature was reached, $\mathrm{H}_{2}$ was stopped and a gas mixture of $\mathrm{C}_{2} \mathrm{H}_{2}(20 \mathrm{~mL} / \mathrm{min})$ and $\operatorname{Ar}(200 \mathrm{~mL} / \mathrm{min}$ ) (Figure 1eII) was immediately introduced into the furnace to synthesize Fe-C@C nanoparticles for 60 min using CVD. Finally, Fe-C@C nanoparticles (Figure 1f) supported on NaCl were obtained after the reactor was cooled to room temperature under an Ar atmosphere (100 $\mathrm{mL} / \mathrm{min})$. The Fe-C@C nanoparticles synthesized at 300, 350, 400, and $450{ }^{\circ} \mathrm{C}$ were indexed as Samples 1, 2, 3, and 4 , respectively.

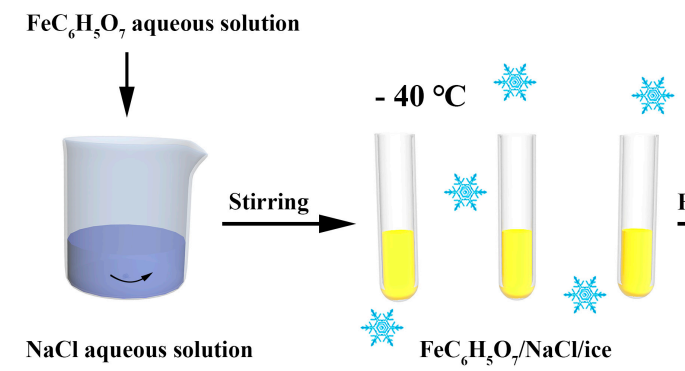

(a) (b)

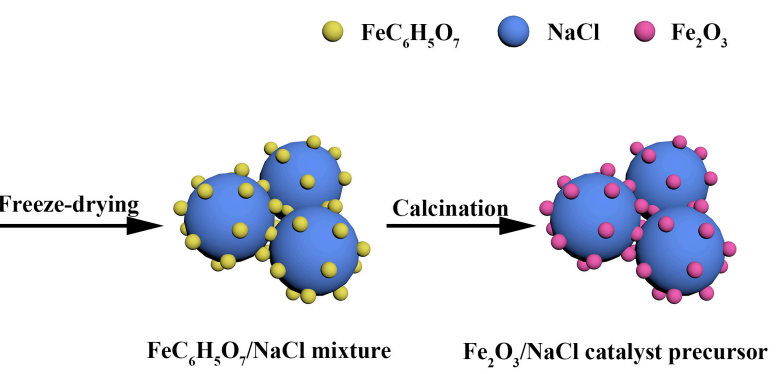

(c)

(d)

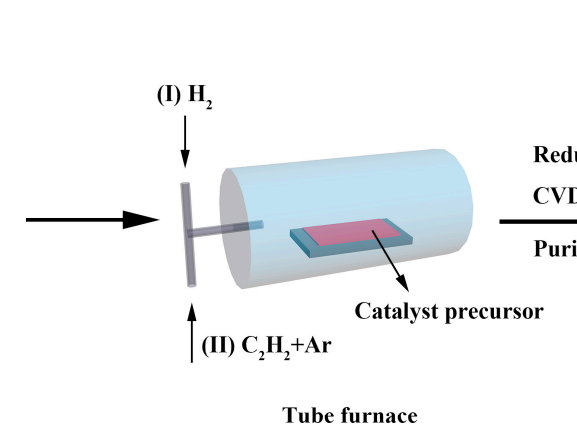

(e)

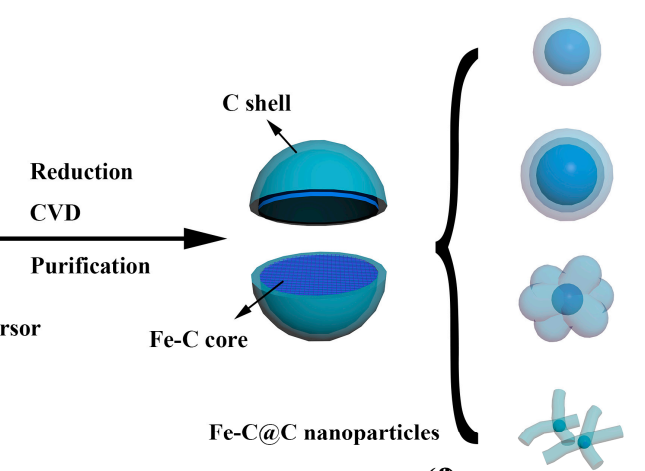

(f)

Figure 1. Illustration of the fabrication of Fe-C@C nanoparticles. (a) Preparation of $\mathrm{FeC}_{6} \mathrm{H}_{5} \mathrm{O}_{7} / \mathrm{NaCl}$ mixed solution. (b) Formation of $\mathrm{FeC}_{6} \mathrm{H}_{5} \mathrm{O}_{7} / \mathrm{NaCl} /$ ice mixture. (c) $\mathrm{FeC}_{6} \mathrm{H}_{5} \mathrm{O}_{7} / \mathrm{NaCl}$ mixture obtained via freeze-drying. (d) Formation of $\mathrm{Fe}_{2} \mathrm{O}_{3} / \mathrm{NaCl}$ catalyst precursor. (e) Synthesis of Fe-C@C nanoparticles via CVD. (f) Fe-C@C nanoparticles with adjustable structures.

\subsection{Purification of Fe-C@C Nanoparticles}

First, the synthesized black Fe-C@C nanoparticle powders supported on $\mathrm{NaCl}$ were washed by sonication in distilled water for $30 \mathrm{~min}$. Then, the sonicated liquid was placed in centrifuge tubes and centrifuged at 10,000 rpm for $10 \mathrm{~min}$. Finally, a plastic dropper was used to remove the liquid phase containing $\mathrm{NaCl}$ in the centrifuge tubes and the precipitate was collected and subsequently dried in a vacuum drying oven at $60{ }^{\circ} \mathrm{C}$ for $12 \mathrm{~h}$ to obtain the purified Fe-C@C nanoparticles. 


\subsection{Adsorption Experiments}

To investigate the adsorptive performance of the synthesized Fe-C@C nanoparticles, adsorption experiments were carried out to measure their adsorption of MB. For adsorption isotherm experiments, Fe-C@C nanoparticles $(10 \mathrm{mg})$ were added to $10-\mathrm{mL} \mathrm{MB}$ aqueous solutions of various concentrations $(10,20,30,50,75,100,150,200,250$, and $300 \mathrm{mg} / \mathrm{L})$ to form suspensions. After the suspensions were sonicated for $1 \mathrm{~min}$ and oscillated in a shaker at $80 \mathrm{rpm}$ for $24 \mathrm{~h}$, the supernatants were separated by centrifugation at 10,000 rpm for $10 \mathrm{~min}$. The concentrations of MB in the supernatants were determined using ultraviolet-visible (UV-Vis) spectroscopy by measuring the absorbance at $664 \mathrm{~nm}$ (characteristic absorbance of $\mathrm{MB}$ ) relative to a calibration curve recorded under the same conditions. The adsorption capacity of Fe-C@C nanoparticles for MB at equilibrium was calculated by Equation (1).

$$
q_{\mathrm{e}}=\frac{\left(c_{0}-c_{\mathrm{e}}\right) V}{m}
$$

where $q_{\mathrm{e}}$ is the equilibrium adsorption capacity $(\mathrm{mg} / \mathrm{g}) ; c_{0}$ and $c_{\mathrm{e}}$ are the initial and equilibrium concentrations $(\mathrm{mg} / \mathrm{L})$ of $\mathrm{MB}$, respectively; $V$ is the volume (L) of the MB aqueous solution; and $m$ is the mass (g) of Fe-C@C nanoparticles in the suspension. For the removal rate experiments, suspensions formed by adding Fe-C@C nanoparticles $(10 \mathrm{mg}$ ) to a $\mathrm{MB}$ aqueous solution (concentration $=50 \mathrm{mg} / \mathrm{L}$ ) were sonicated for $1 \mathrm{~min}$ and then oscillated for 5, 10, 15, 20, 25, 30, 40, 50 or $60 \mathrm{~min}$. The supernatants were separated by centrifugation at 10,000 rpm for $10 \mathrm{~min}$, and their $\mathrm{MB}$ concentrations were determined as in the adsorption isotherm experiments.

\subsection{Characterization}

X-ray diffraction (XRD; D/Max-2500, Rigaku Co., Tokyo, Japan) patterns were recorded to analyze the phase composition of the synthetic products within the angle range of $20^{\circ}-90^{\circ}(2 \theta)$ in steps of $0.02^{\circ}$. The morphologies and microstructures of the powder samples were observed using field emission scanning electron microscopy (FESEM; Nova Nano SEM450, FEI, Hillsboro, OR, USA) and high-resolution transmission electron microscopy (HRTEM; Tecnai G2 F20, FEI, Hillsboro, OR, USA). To evaluate the thermal-oxidative stability and carbon content of the samples, thermogravimetric analysis-differential scanning calorimetry (TGA-DSC; SDT Q600 TGA, TA Instruments, New Castle, DE, USA) was performed in an air atmosphere from 25 to $800{ }^{\circ} \mathrm{C}$ with a heating rate of $10^{\circ} \mathrm{C} / \mathrm{min}$. To evaluate the crystallinity of the carbon layers, Raman spectra were obtained using a DXR Raman microscope (Thermo Fisher Scientific, Waltham, MA, USA) equipped with an $\mathrm{Ar}^{+}$laser with a 1064-nm line as the excitation source. A vibrating sample magnetometer (7407 VSM, Lake Shore Cryotronics, Westerville, OH, USA) was used to characterize the magnetic properties of the Fe-C@C nanoparticles at $25{ }^{\circ} \mathrm{C} . \mathrm{N}_{2}$ adsorption-desorption isotherms were measured at $-196{ }^{\circ} \mathrm{C}$ using an adsorption instrument (ASAP 2020M+C, Micromeritics Instruments Co., Norcross, GA, USA), and the specific surface area, pore volume, and pore size were calculated using the Brunauer-Emmett-Teller (BET) and Barret-Joyner-Halender (BJH) methods [22,23]. UV-Vis spectra were obtained using a UV-Vis spectrophotometer (U-3900H, Hitachi High-Technologies, Fukuoka, Japan) at a fixed wavelength of $664 \mathrm{~nm}$ to analyze the adsorptive performance of the Fe-C@C nanoparticles.

\section{Results and Discussion}

\subsection{Morphology and Structure of Fe-C@C Nanoparticles}

Figure 2 shows the XRD patterns of purified Fe-C@C nanoparticles synthesized at different temperatures. No obvious diffraction peak belonging to the $\mathrm{NaCl}$ crystal is seen in the XRD pattern of any of the samples, inferring the complete removal of the $\mathrm{NaCl}$ supporter by simple washing and centrifugation. For Samples 1, the diffraction peaks at $2 \theta=44.7^{\circ}$ and $82.3^{\circ}$ can be indexed to the (110) and (211) planes of Fe with a body-centered cubic structure (ICDD Card, no. 89-7194), respectively. The other low diffraction peaks can be indexed to the $\mathrm{Fe}_{3} \mathrm{C}$ phase (ICDD Card, no. 76-1877) based on 
their positions and relative intensities. The characteristic peaks belonging to the crystalline graphite phase are not observed because of the low content and crystallinity of the deposited graphite phase in these samples, which is consistent with the literature [20,24]. For Sample 2, the diffraction peaks of Fe at $44.7^{\circ}$ and $82.3^{\circ}$ become weakened obviously. With a growth temperature of $400{ }^{\circ} \mathrm{C}$ (Sample 3), the diffraction peaks of $\mathrm{Fe}$ disappear and only the characteristic peaks of $\mathrm{Fe}_{3} \mathrm{C}$ remain. Furthermore, compared with the XRD patterns of Samples 1 and 2, that of Sample 3 has more low-intensity diffraction peaks at $2 \theta=37.8^{\circ}, 46.0^{\circ}$, and $48.7^{\circ}$, which can be associated with the (021), (211), and (113) planes of $\mathrm{Fe}_{3} \mathrm{C}$, respectively, confirming that Sample 3 is mainly composed of $\mathrm{Fe}_{3} \mathrm{C}$. Similar to Samples 1 and 2, the characteristic peaks belonging to the crystalline graphite phase are still not observed. The diffraction peaks of $\mathrm{Fe}_{3} \mathrm{C}$ for Sample 4, synthesized at $450{ }^{\circ} \mathrm{C}$, are similar to those of Sample 3, except for the appearance of a broad halo peak around $2 \theta=26.5^{\circ}$, which can be associated with the (002) plane of graphite. This broadened diffraction peak suggests that the synthesized carbon products in Sample 4 have more structural defects than the crystalline graphite. The XRD results in Figure 2 show that the metallic phase in the synthesized Fe-C@C nanoparticles transforms from $\mathrm{Fe} / \mathrm{Fe}_{3} \mathrm{C}$ phases in Samples 1 to a simple $\mathrm{Fe}_{3} \mathrm{C}$ phase in Samples 2, 3, and 4. This transformation can be attributed to the high reactivity between $\mathrm{Fe}$ and $\mathrm{C}$ atoms at higher synthesis temperatures [25].

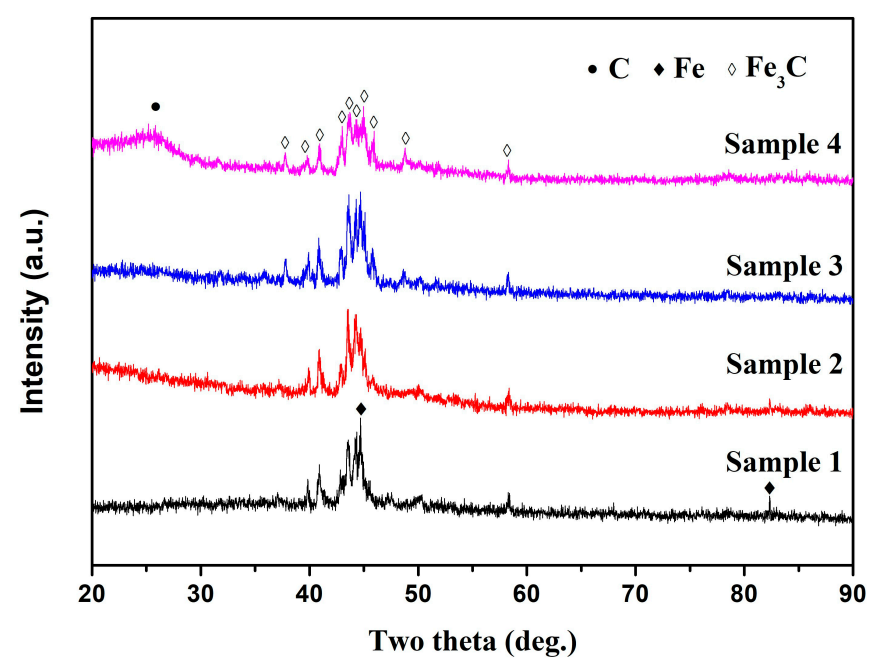

Figure 2. X-ray diffraction (XRD) patterns of purified Fe-C@C nanoparticles synthesized at different temperatures: Sample $1\left(300^{\circ} \mathrm{C}\right)$, Sample $2\left(350{ }^{\circ} \mathrm{C}\right)$, Sample $3\left(400^{\circ} \mathrm{C}\right)$, and Sample $4\left(450^{\circ} \mathrm{C}\right)$.

The SEM and TEM images in Figure 3 show the morphology and microstructure of the Fe-C@C nanoparticles synthesized at different temperatures. The morphology and microstructure of the synthesized Fe-C@C nanoparticles vary with the synthesis temperature, and there are no bare Fe-C nanoparticles, indicating that the carbon encapsulation layers were successfully deposited onto the surfaces of the Fe catalysts. Figure 3a shows that the Fe-C@C nanoparticles in Sample 1, synthesized at $300{ }^{\circ} \mathrm{C}$, are quasi-spherical. According to the particle size distribution (inset of Figure 3a) based on the SEM analysis, the diameters of the nanoparticles vary from 50 to $220 \mathrm{~nm}$, with an average diameter of $126.7 \mathrm{~nm}$. The energy-dispersive X-ray spectroscopy (EDS) image as an inset of Figure 3a shows that the main elements of Sample 1 are $\mathrm{C}, \mathrm{Fe}$, and $\mathrm{O}$ without the existence of $\mathrm{Cl}$ and $\mathrm{Na}$, further indicating that the $\mathrm{NaCl}$ supporter was completely removed from the Fe-C@C nanoparticles. Figure 3b shows that the synthesized Fe-C@C nanoparticles of Sample 1 have a typical core-shell structure, with Fe-C cores and amorphous carbon shells. The carbon shells encapsulating the Fe-C cores are thin (approximately $20 \mathrm{~nm}$ thick) due to the low catalytic activity of the Fe nanoparticles at the low synthesis temperature [26]. The EDS analysis inserted in Figure $3 \mathrm{~b}$ shows that the main elements of Sample 1 are $\mathrm{Fe}, \mathrm{C}$, and $\mathrm{Cu}$ coming from the $\mathrm{Cu}$ TEM grid. Figure $3 \mathrm{c}$ shows that Sample 2, synthesized at $350{ }^{\circ} \mathrm{C}$, exhibits a rough and irregular particle shape compared with Sample 1 (Figure 3a) and has a larger average diameter $(165.2 \mathrm{~nm})$ than Sample 1. The larger diameter results from the accelerated decomposition 
of the carbon source caused by the enhanced catalytic activity of Fe catalyst nanoparticles and the reactivity of $\mathrm{Fe}$ and $\mathrm{C}$ atoms at the higher synthesis temperature $[27,28]$. Figure $3 \mathrm{~d}$ also shows the rough and irregular particle shape of Sample 2, and the synthesized Fe-C@C nanoparticles have a thicker carbon shell (approximately $70 \mathrm{~nm}$ ) compared with that of Sample 1. Figure 3e shows that the Fe-C@C nanoparticles of Sample 3, synthesized at $400{ }^{\circ} \mathrm{C}$, exhibit carbon shells diverging in different directions. The particle size distribution (inset of Figure 3e) shows that the diameters of Sample 3 nanoparticles are in the range of 121-309 $\mathrm{nm}$, with an average diameter of $189.3 \mathrm{~nm}$. The TEM image in Figure $3 \mathrm{f}$ further shows that the Fe-C@C nanoparticles have a "flower-like" structure, that is, external rough and divergent carbon shells and internal metal cores. These flower-like Fe-C@C nanoparticles have coarse surfaces and many porous channels, and thus, they can provide more adsorption sites for contaminants, which help improving the adsorption capacity of the nanoparticles when used as adsorbents in treating dye wastewater. The HRTEM image in the upper inset of Figure $3 f$ shows that the Fe-C particles are closely connected to the carbon-encapsulated layers, and their lattice fringes can be clearly observed. The interplanar spacing of 0.185 and $0.200 \mathrm{~nm}$ can be indexed to the (122) and (103) planes of $\mathrm{Fe}_{3} \mathrm{C}$, respectively [25]. The carbon-encapsulated layers maintain the state of short-range order (with an interplanar spacing of $0.343 \mathrm{~nm}$ ) and long-range disorder, like amorphous carbon. The selected area electron diffraction (SAED) pattern in the lower inset of Figure $3 \mathrm{f}$ shows two diffraction rings that are attributed to the (103) and (130) planes of $\mathrm{Fe}_{3} \mathrm{C}$, respectively, further confirming that the $\mathrm{Fe}-\mathrm{C}$ cores are composed of polycrystalline $\mathrm{Fe}_{3} \mathrm{C}$. When the synthesis temperature is $450^{\circ} \mathrm{C}$ for Sample 4 , short and thick carbon nanofibers (CNFs), rather than Fe-C@C nanoparticles, are synthesized, as shown in Figure 3g,h, because of the enhanced catalytic activity of the Fe catalysts [29], which reduces the purity of the synthesized Fe-C@C nanoparticles.

Figure 4 shows the Raman spectra obtained to evaluate the degree of graphitization of the Fe-C@C nanoparticles synthesized at different temperatures. All samples have two Raman bands at 1345 $\mathrm{cm}^{-1}$ (D band) and $\sim 1600 \mathrm{~cm}^{-1}$ (G band), which are associated with the vibrations of carbon atoms with dangling bonds for the in-plane terminations of disordered graphite (D) and the vibrations in $\mathrm{sp}^{2}$-bonded carbon atoms in a $2 \mathrm{D}$ hexagonal lattice $(\mathrm{G})$, respectively [30]. The relative intensity $I_{\mathrm{D}} / I_{\mathrm{G}}$ of Samples 1, 2, 3, and 4 is calculated to be 1.12, 1.05, 0.97, and 0.95, respectively. Although the degree of graphitization of the Fe-C@C nanoparticles increases with increasing synthesis temperature, the values of $I_{\mathrm{D}} / I_{\mathrm{G}}$ for all samples are larger than that of graphite carbon, indicating the existence of many structural defects in the synthesized carbon shells. These defects are conducive to forming abundant porous structures that improve the adsorption property of the Fe-C@C nanoparticles.

Figure 5 shows the TGA-DSC curves of the Fe-C@C nanoparticles synthesized at different temperatures. During the heating process, all the samples exhibit similar exothermic behavior at different oxidation temperatures, which is associated with various changes in sample weight. The weight increase in Sample 1 at the heating stage from 152 to $402{ }^{\circ} \mathrm{C}$ is due to the oxidation of iron nanoparticles to iron oxide. An oxidation exothermic peak appears at $384^{\circ} \mathrm{C}$ with an increase in weight of approximately $15.2 \mathrm{wt} \%$. This is the comprehensive effect of the oxidation of carbon encapsulation layers and $\mathrm{Fe}-\mathrm{C}$ cores, that is, the conversion of carbon to carbon dioxide leading to a decrease in weight, the formation of iron oxide causing an increase in weight, and the oxidations of carbon and iron are all part of the exothermic reaction. Similarly, Sample 2 exhibits a slight weight increase at the initial heating stage from 192 to $304{ }^{\circ} \mathrm{C}$. On the other hand, Sample 2 losts weight between 304 and $470{ }^{\circ} \mathrm{C}$ because of its higher carbon content. Approximately $76.2 \mathrm{wt} \%$ of the sample remains after the heating process. An oxidation exothermic peak appears at approximately $386^{\circ} \mathrm{C}$. Sample 3 has only a single-step weight loss and stops losing weight near $500^{\circ} \mathrm{C}$. The oxidation exothermic peak shifts right to approximately $445^{\circ} \mathrm{C}$, indicating the enhanced thermal-oxidative stability of the Fe-C@C nanoparticles. Approximately $49.3 \mathrm{wt} \%$ of Sample 3 remains after performing the TGA. The weight loss for Sample 4 is obviously greater than that of the other samples, and only approximately $33.4 \mathrm{wt}$ $\%$ of the sample remains after TGA analysis, indicating a higher carbon content. The sample stops 
losing weight near $536^{\circ} \mathrm{C}$. The oxidation exothermic peak at approximately $499^{\circ} \mathrm{C}$ indicates the higher thermal-oxidative stability of Sample 4.
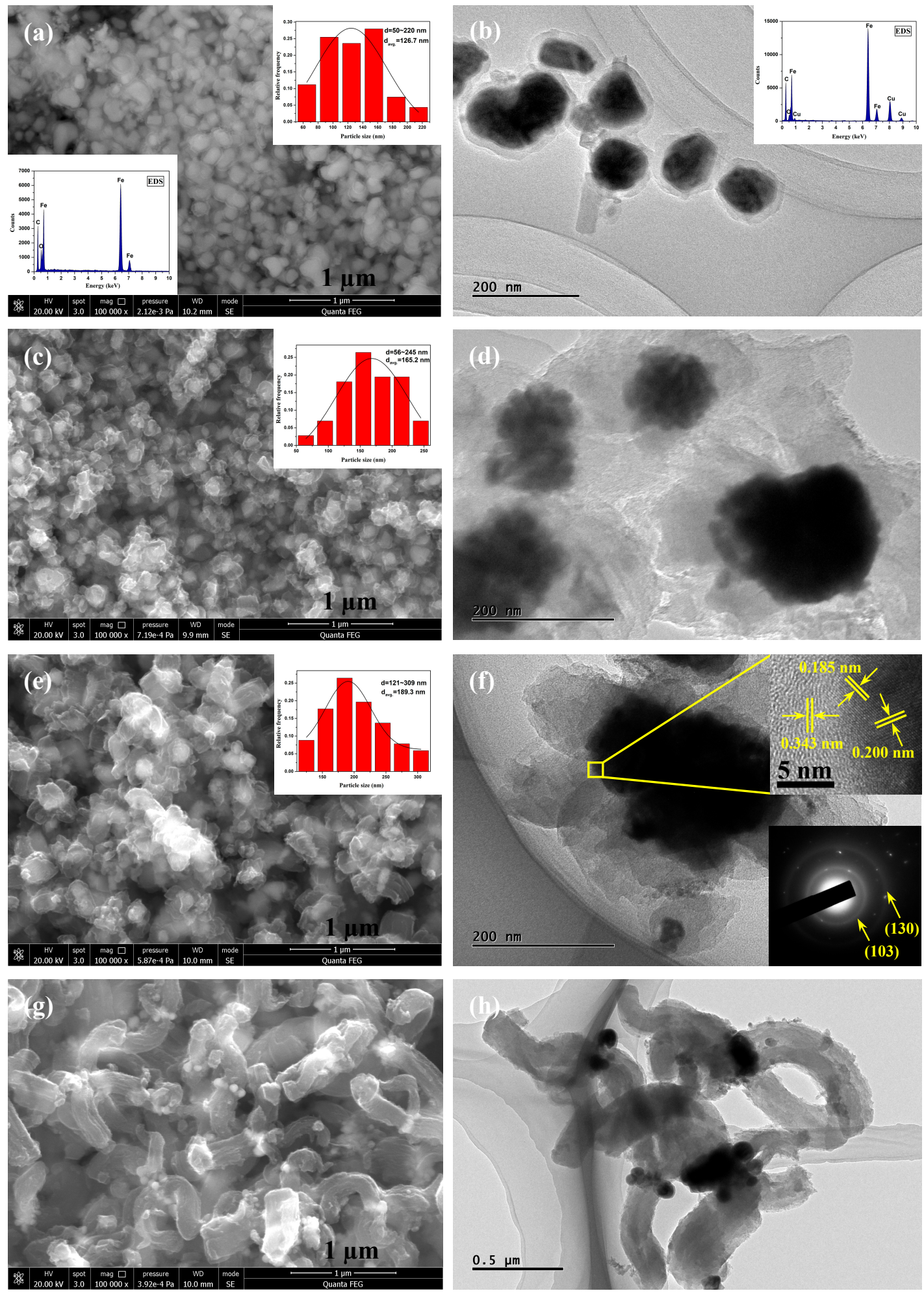

Figure 3. Scanning electron microscopy (SEM) and transmission electron microscopy (TEM) images of Fe-C@C nanoparticles: (a,b) Sample 1, (c,d) Sample 2, (e,f) Sample 3, and (g,h) Sample 4 (Inset of a: the energy-dispersive X-ray spectroscopy (EDS) analysis and particle size distribution based on SEM; inset of b: the EDS analysis based on TEM; insets of $\mathrm{c}$ and e: the particle size distribution; inset of $\mathrm{f}$ : HRTEM image of the square region and the diffraction pattern). 


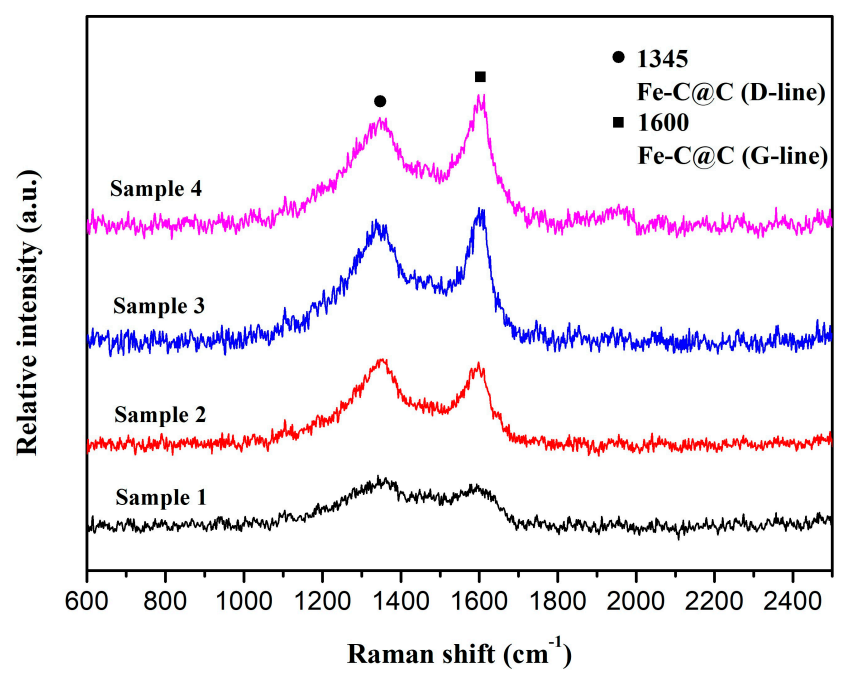

Figure 4. Raman spectra of Fe-C@C nanoparticles.

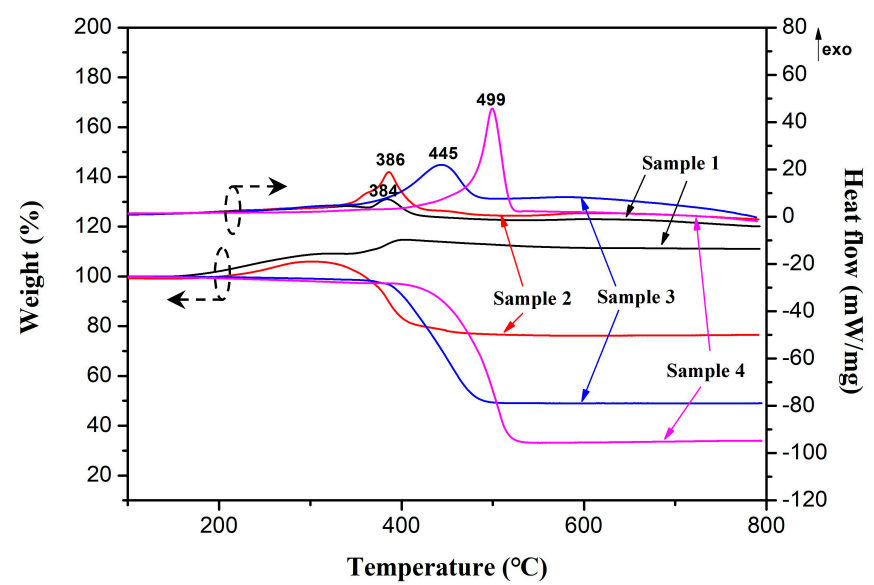

Figure 5. Thermogravimetric analysis-differential scanning calorimetry (TGA-DSC) curves of Fe-C@C nanoparticles.

Figure 6 and Table 1 show the $\mathrm{N}_{2}$ adsorption-desorption isotherms, pore size distributions, and textural parameters of the synthesized Fe-C@C nanoparticles. The isotherms in Figure 6a all exhibit hysteresis loops from relative pressure 0.4 to 1.0 because of the irreversibility between the adsorption and desorption processes. Because $\mathrm{N}_{2}$ fills the spaces in the synthesized Fe-C@C nanoparticles, the amount of adsorption increases dramatically as the relative pressure approaches 1.0 [31]. The $\mathrm{N}_{2}$ adsorption-desorption isotherms of Samples 1 and 2 exhibit two narrow hysteresis loops, that is, the close intervals between adsorption and desorption branches, indicating that there are fewer pores in the synthesized samples. Accordingly, Figure $6 \mathrm{~b}$ shows that Samples 1 and 2 have only weak peaks that are attributed to the clearance of carbon layers, and Table 1 shows that their specific surface areas and pore volumes are smaller than those of Samples 3 and 4. According to the IUPAC classification [32,33], the isotherms of Samples 3 and 4 can be classified as typical type IV curves with protuberant hysteresis loops, indicating the coexistence of micropore and mesopore in the materials [34,35]. In Figure 6b, Sample 3 exhibits a broad peak ranging from 1.5 to $4.0 \mathrm{~nm}$ and centers at approximately $2.3 \mathrm{~nm}$, inferring that many pores are distributed in the outer carbon layer. The specific surface area and pore volume of Sample 3 are calculated to be $169.4 \mathrm{~m}^{2} / \mathrm{g}$ and $0.50 \mathrm{~cm}^{3} / \mathrm{g}$, respectively, as shown in Table 1. The pore size distribution of Sample 4 is similar to that of Sample 3, but its specific surface area $\left(124.7 \mathrm{~m}^{2} / \mathrm{g}\right)$ and pore volume $\left(0.44 \mathrm{~cm}^{3} / \mathrm{g}\right)$ are lower. From the above experimental results, it can be concluded that Sample 3 possesses the high specific surface area and pore volume because of its "flower-like" structure. The porous characteristic provides a large number of adsorption 
sites for pollutants and is conducive to enhancing the adsorption capacity and removal rate of the Fe-C@C nanoparticles.

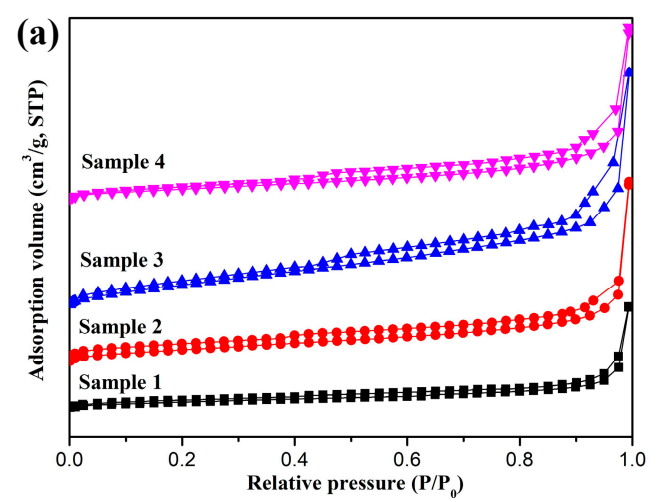

Figure 6. (a) $\mathrm{N}_{2}$ adsorption-desorption isotherms and (b) pore size distributions of Fe-C@C nanoparticles.

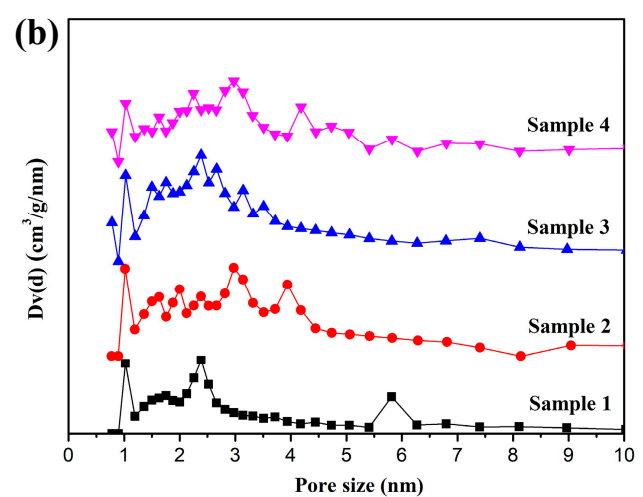

Table 1. Specific surface area, pore volume, and pore size of Fe-C@C nanoparticles.

\begin{tabular}{cccc}
\hline Materials & Specific Surface Area $\left(\mathbf{m}^{2} / \mathbf{g}\right)$ & Pore Volume $\left(\mathbf{c m}^{3} / \mathbf{g}\right)$ & Pore Size $(\mathbf{n m})$ \\
\hline Sample 1 & 79.4 & 0.25 & 2.37 \\
Sample 2 & 105.5 & 0.35 & 3.14 \\
Sample 3 & 169.4 & 0.50 & 2.18 \\
Sample 4 & 124.7 & 0.44 & 2.83 \\
\hline
\end{tabular}

\subsection{Magnetic Properties}

It is very important to evaluate the magnetic properties of the synthesized Fe-C@C nanoparticles to separate the adsorbents from wastewater. Table 2 and Figure 7 present the magnetic parameters and hysteresis loops of the Fe-C@C nanoparticles, respectively. The saturation magnetization $\left(M_{\mathrm{S}}\right)$ and coercive force $\left(H_{\mathrm{c}}\right)$ of the synthesized Fe-C@C nanoparticles are in the range of 21.533-74.793 $\mathrm{emu} / \mathrm{g}$ and 358.83-621.33 Oe, respectively, which are all higher than the reported values of Fe-C@C nanoparticles with similar composition $[11,36]$. The ratios of the remanence to saturation magnetization $\left(M_{\mathrm{r}} / M_{\mathrm{s}}\right)$ are in the range of $0.102-0.212$, which indicates the improved ferromagnetism of the Fe-C@C nanoparticles. The magnetic properties of the Fe-C@C nanoparticles synthesized at different temperatures vary with synthesis temperature. Figure 7 shows that the magnetization of the synthesized Fe-C@C nanoparticles yields square hysteresis loops with periodically varying magnetic fields. However, the squareness of the hysteresis loops is compressed as the synthesis temperature increases, indicating a gradual reduction in $M_{\mathrm{s}}$, which is in accordance with the magnetic parameters in Table 2. In addition, the $M_{\mathrm{S}}$ of Samples 1-4 are all lower than that of bulk Fe (218 emu/g) and bulk $\mathrm{Fe}_{3} \mathrm{C}(140 \mathrm{emu} / \mathrm{g})[37,38]$. This decrease in $M_{\mathrm{s}}$ can be attributed to the carbon layers that encapsulate the Fe-C cores. Carbon is a diamagnetic substance that weakens the $M_{\mathrm{S}}$ of Fe-C@C nanoparticles $[39,40]$. As the synthesis temperature increases, the content of diamagnetic carbon in the Fe-C@C nanoparticles increases, resulting in a further decrease in $M_{\mathrm{s}}$. Furthermore, the transformation of Fe in Samples 1 and 2 to $\mathrm{Fe}_{3} \mathrm{C}$ in Samples 3 and 4 also causes the decrease in $M_{\mathrm{s}}$. In addition, the $H_{\mathrm{c}}$ of the Fe-C@C nanoparticles increases with the increase in the synthesis temperature, as seen in Table 2. This can be attributed to the weakened dipole interaction owing to the thickened carbon layers deposited on the Fe-C cores [41]. The $H_{\mathrm{C}}$ of the synthesized Fe-C@C nanoparticles is much greater than that of pure bulk $\mathrm{Fe}(\sim 1 \mathrm{Oe})$ or $\mathrm{Fe}_{3} \mathrm{C}$ (usually $\left.<100 \mathrm{Oe}\right)$. This is due to the effect of the nanoscale Fe-C cores resulting in a high $H_{\mathrm{c}}$ [42]. As a result, the synthesized Fe-C@C nanoparticles have improved ferromagnetism that allows them to quickly respond to an external magnetic field, which is beneficial in separating them from wastewater. 


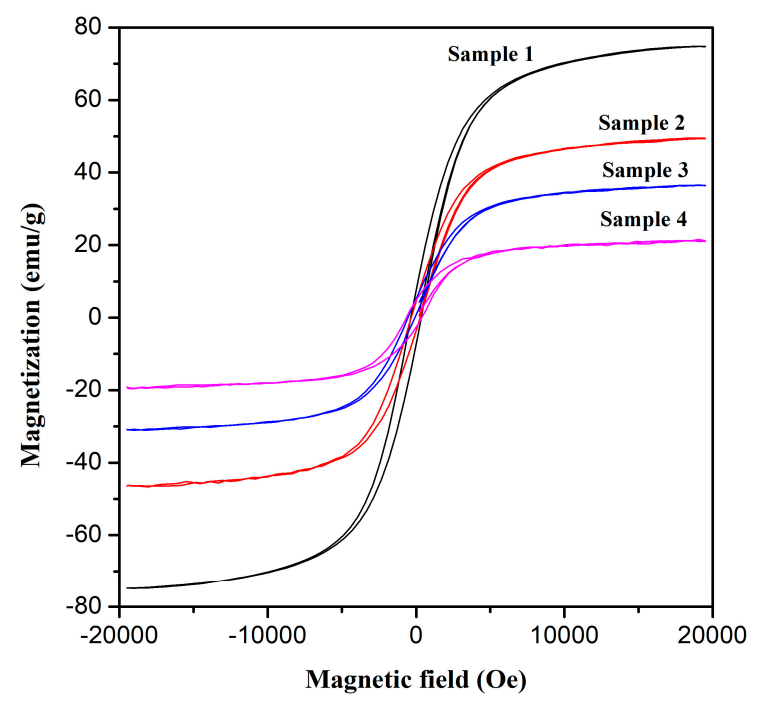

Figure 7. Hysteresis loops of Fe-C@C nanoparticles.

Table 2. Magnetic parameters of Fe-C@C nanoparticles.

\begin{tabular}{ccccc}
\hline Materials & $\boldsymbol{M}_{\mathbf{s}}(\mathbf{e m u} / \mathbf{g})$ & $\boldsymbol{M}_{\mathbf{r}}(\mathbf{e m u} / \mathbf{g})$ & $\boldsymbol{M}_{\mathbf{r}} / \boldsymbol{M}_{\mathbf{s}}$ & $\boldsymbol{H}_{\mathbf{c}}(\mathbf{O e})$ \\
\hline Sample 1 & 74.793 & 7.5955 & 0.102 & 358.83 \\
Sample 2 & 49.532 & 5.7361 & 0.116 & 426.90 \\
Sample 3 & 36.544 & 5.6221 & 0.154 & 560.61 \\
Sample 4 & 21.533 & 4.5716 & 0.212 & 621.33 \\
\hline
\end{tabular}

\subsection{Adsorption Properties}

The application of Fe-C@C nanoparticles as an adsorbent in separating pollutant from wastewater was investigated using MB as the pollutant. The adsorption behaviors of Samples 1-4 were described using the Langmuir and Freundlich isotherm models (Equations (2) and (3), respectively) [43,44]. The corresponding parameters are given in Table 3.

$$
\begin{aligned}
& \frac{c_{\mathrm{e}}}{q_{\mathrm{e}}}=\frac{1}{K_{\mathrm{L}} Q_{\max }}+\frac{c_{\mathrm{e}}}{Q_{\max }} \\
& \ln q_{\mathrm{e}}=\ln K_{\mathrm{F}}+\frac{1}{n} \ln c_{\mathrm{e}}
\end{aligned}
$$

where $c_{\mathrm{e}}(\mathrm{mg} / \mathrm{L})$ is the equilibrium concentration of $\mathrm{MB}$ in the aqueous solution, $q_{\mathrm{e}}(\mathrm{mg} / \mathrm{g})$ is the equilibrium adsorption capacity, $K_{\mathrm{L}}(\mathrm{L} / \mathrm{mg})$ is the binding constant of the Langmuir adsorption, $Q_{\max }(\mathrm{mg} / \mathrm{g})$ is the maximum adsorption capacity, $K_{\mathrm{F}}\left[(\mathrm{mg} / \mathrm{g}) \cdot(\mathrm{L} / \mathrm{mg})^{1 / n}\right]$ is the Freundlich constant, and $1 / n$ is the Freundlich adsorption intensity parameter. Figure $8 \mathrm{a}-\mathrm{d}$ present the experimental values of $c_{\mathrm{e}}$ and $q_{\mathrm{e}}$ obtained by adsorption isotherm experiments and the fitted curves of the Langmuir and Freundlich isotherm models. The fitted curves of both models match the experimental data well, which indicates the uniform distribution of adsorption sites on the surfaces of the Fe-C@C nanoparticles [31]. The similar correlation coefficients $\left(R^{2}\right)$ in Table 3 are also indicative of the uniform adsorption site distribution. From the Langmuir model, the $Q_{\max }$ values of Samples $1-4$ are 71.28, $75.16,90.14$, and $81.45 \mathrm{mg} / \mathrm{g}$, respectively, as listed in Table 3. Sample 3 has the highest adsorption capacity for MB. The rough and divergent carbon shells of Sample 3, with their porosity, play pivotal roles during the adsorption process via providing more sites for the adsorption of the pollutant, and thus result in a remarkably enhanced adsorption capacity. For the Freundlich model, adsorption is easy when the adsorption intensity $1 / n$ is between 0.1 and 1 , but becomes more difficult when above $1[45,46]$. As listed in Table $3,1 / n$ is in the range of $0.222-0.275$ for Samples $1-4$, which suggests that the Fe-C@C nanoparticles easily adsorb MB in the aqueous solution. Figure 8e presents the 
adsorption capacities $\left(q_{\mathrm{t}}\right)$ of Samples 1-4 measured at various times. All the adsorption curves exhibit a similar trend in the change in $q_{\mathrm{t}}$ and reach equilibrium within $30 \mathrm{~min}$, suggesting fast removal of MB. After adsorption for $30 \mathrm{~min}, q_{\mathrm{t}}$ of Sample 3 is calculated to be $37.2 \mathrm{mg} / \mathrm{g}$ when the initial concentration of the $\mathrm{MB}$ aqueous solution is $50 \mathrm{mg} / \mathrm{L}$, which is higher than $q_{\mathrm{t}}$ of Sample 1, 2, and 4, i.e., 33.6, 34.4, and $34.5 \mathrm{mg} / \mathrm{g}$, respectively. Further experiments confirm that Sample 3 has preferable adsorption behavior. Figure $8 \mathrm{f}$ shows the $\mathrm{MB}$ aqueous solution before and after adsorption via Sample 3 over $30 \mathrm{~min}$ and magnetic separation by an external magnet. The original blue MB aqueous solution becomes black after adsorption and removal of MB by Sample 3. Further, the solution becomes clear after the magnetic separation of Fe-C@C nanoparticles via an external magnet. Therefore, the flower-like Fe-C@C nanoparticles, with their excellent adsorptive and magnetic properties, can be used as an efficient adsorbent in treating dye wastewater.
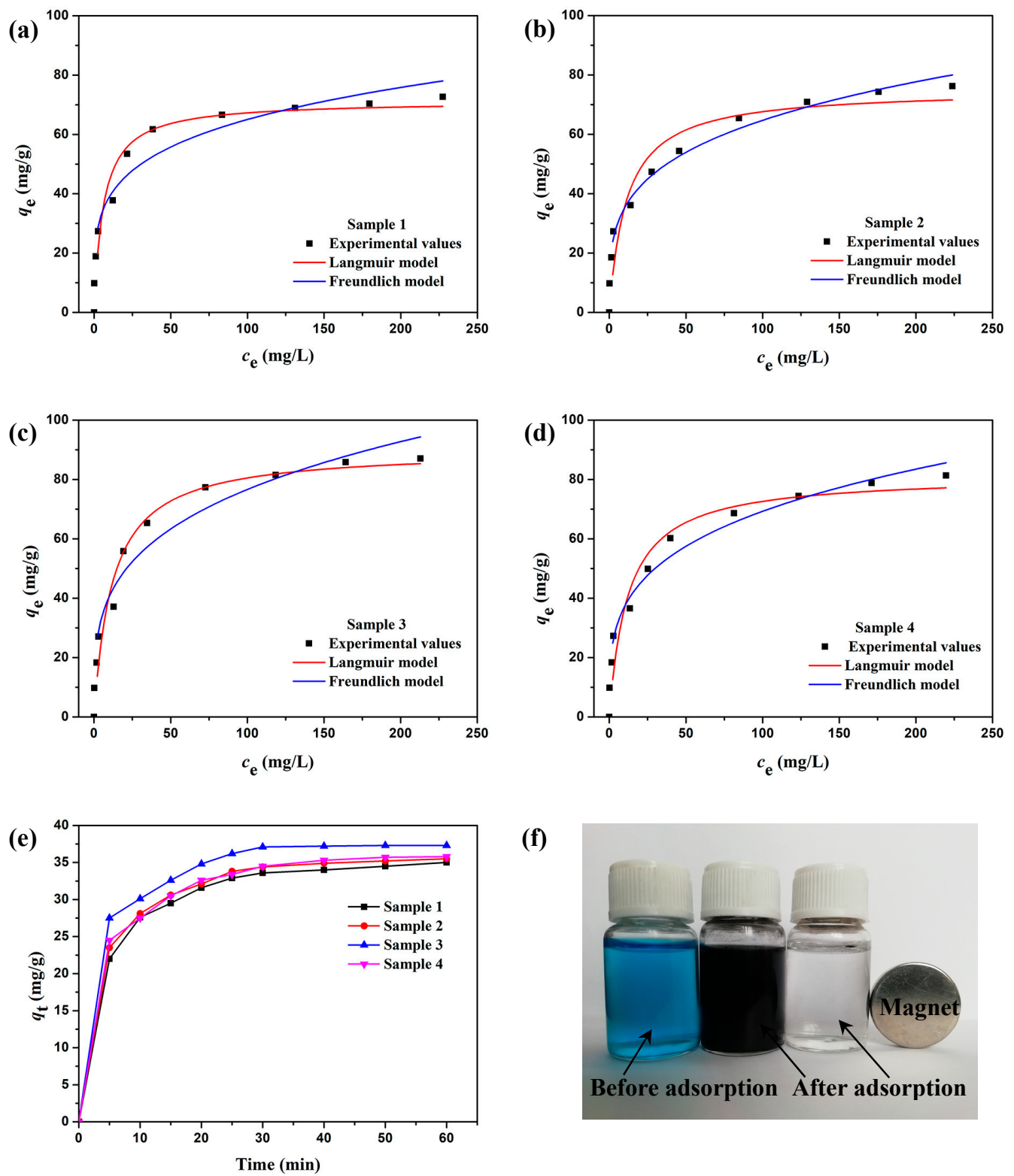

(f)

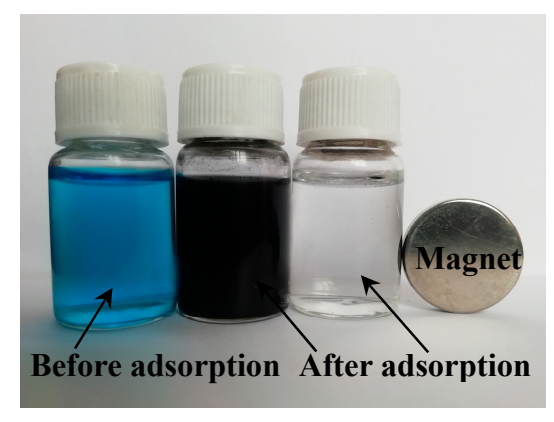

Figure 8. (a-d) Experimental values of $c_{\mathrm{e}}$ and $q_{\mathrm{e}}$ obtained by adsorption isotherm experiments and the fitted curves of Langmuir and Freundlich isotherm models for Samples 1-4. (e) Adsorption capacities $q_{\mathrm{t}}$ of Samples 1-4 measured at various times. (f) Photograph of a MB aqueous solution (30 mg/L) before and after adsorption via Sample 3 over $30 \mathrm{~min}$ and magnetic separation by an external magnet. 
Table 3. Langmuir and Freundlich isotherm model parameters.

\begin{tabular}{ccccccc}
\hline \multirow{2}{*}{ Materials } & \multicolumn{3}{c}{ Langmuir Model } & \multicolumn{3}{c}{ Freundlich Model } \\
\cline { 2 - 7 } & $\boldsymbol{Q}_{\max }(\mathbf{m g} / \mathbf{g})$ & $\boldsymbol{K}_{\mathbf{L}}(\mathbf{L} / \mathbf{m g})$ & $\boldsymbol{R}^{\mathbf{2}}$ & $\left.\boldsymbol{K}_{\mathbf{F}}[\mathbf{( m g} / \mathbf{g}) \cdot(\mathbf{L} / \mathbf{m g})^{\mathbf{1} / \boldsymbol{n}}\right]$ & $\mathbf{1 / n}$ & $\boldsymbol{R}^{\mathbf{2}}$ \\
\hline Sample 1 & 71.28 & 0.167 & 0.937 & 23.42 & 0.222 & 0.940 \\
Sample 2 & 75.16 & 0.090 & 0.897 & 19.26 & 0.263 & 0.987 \\
Sample 3 & 90.14 & 0.083 & 0.955 & 21.58 & 0.275 & 0.952 \\
Sample 4 & 81.45 & 0.083 & 0.925 & 20.07 & 0.269 & 0.979 \\
\hline
\end{tabular}

\section{Conclusions}

Novel flower-like Fe-C@C nanoparticles with integrated adsorptive and magnetic properties were successfully fabricated for use as adsorbing materials. Via freeze-drying, the Fe metallic source was loaded on a $\mathrm{NaCl}$ supporter, after which the combination was easy purified via simple washing and centrifugation to obtain high-purity Fe-C@C nanoparticles. Using the CVD method, the thickness, morphology, and structure of the carbon layers deposited on the Fe catalyst surfaces were adjusted by changing the synthesis temperature. The optimal Fe-C@C nanoparticles, synthesized at $400{ }^{\circ} \mathrm{C}$, exhibited a divergently "flower-like" morphology, with coarse surfaces and many porous channels. Their Raman spectra revealed a lower degree of graphitization, suggesting the existence of many structural defects in the synthesized carbon shells that help in the formation of abundant porous structures. TGA-DSC analysis showed the enhanced thermal-oxidative stability of the flower-like Fe-C@C nanoparticles. $\mathrm{N}_{2}$ adsorption-desorption isotherms confirmed their porosity, with high specific surface area $\left(169.4 \mathrm{~m}^{2} / \mathrm{g}\right)$ and pore volume $\left(0.50 \mathrm{~cm}^{3} / \mathrm{g}\right)$, which can provide many adsorption sites for pollutants and can enhance the adsorption capacity and pollutant removal rate. Adsorption experiments showed that the flower-like Fe-C@C nanoparticles possessed high adsorption capacity $(90.14 \mathrm{mg} / \mathrm{g})$ and fast removal of the pollutant MB. In addition, the synthesized Fe-C@C nanoparticles exhibited improved ferromagnetism, which facilitates the separation of adsorbents from dye wastewater. With these characteristics, the novel flower-like Fe-C@C nanoparticles have great potential as adsorbents in the treatment of dye wastewater.

Author Contributions: Formal Analysis, L.Z., H.L. and C.L.; Investigation, X.D. and B.L.; Writing-Original Draft Preparation, L.Z., X.D. and H.W.; Writing-Review \& Editing, B.L., H.L.; Supervision, H.L., C.L.; Project Administration, B.L. and H.L.

Funding: This work was supported by the National Natural Science Foundation of China (No. 51201056) and the Natural Science Foundation of Hebei Province of China (No. E2015202037).

Conflicts of Interest: The authors declare no conflict of interest.

\section{References}

1. Amaia, M.; Ignacio, L.J.; Ana, D.L. Analysis of primary degradation and decolourization of dyes in water by an $\mathrm{H}_{2} \mathrm{O}_{2}$ /UV advanced oxidation process. J. Adv. Oxid. Technol. 2008, 11, 573-582. [CrossRef]

2. Crini, G. Non-conventional low-cost adsorbents for dye removal: A review. Bioresour. Technol. 2006, 97, 1061-1085. [CrossRef] [PubMed]

3. Qadri, S.; Ganoe, A.; Haik, Y. Removal and recovery of acridine orange from solutions by use of magnetic nanoparticles. J. Hazard. Mater. 2009, 169, 318-323. [CrossRef] [PubMed]

4. Qu, S.; Huang, F.; Yu, S.N.; Chen, G.; Kong, J.L. Magnetic removal of dyes from aqueous solution using multi-walled carbon nanotubes filled with $\mathrm{Fe}_{2} \mathrm{O}_{3}$ particles. J. Hazard. Mater. 2008, 160, 643-647. [CrossRef]

5. Zhao, G.X.; Jiang, L.; He, Y.D.; Li, J.X.; Dong, H.L.; Wang, X.K.; Hu, W.P. Sulfonated graphene for persistent aromatic pollutant management. Adv. Mater. 2011, 23, 3959-3963. [CrossRef]

6. Zhao, G.X.; Wen, T.; Chen, C.L.; Wang, X.K. Synthesis of graphene-based nanomaterials and their application in energy-related and environmental-related areas. RSC Adv. 2012, 2, 9286-9303. [CrossRef] 
7. Zhang, Y.X.; Xu, S.C.; Luo, Y.Y.; Pan, S.S.; Ding, H.L.; Li, G.H. Synthesis of mesoporous carbon capsules encapsulated with magnetite nanoparticles and their application in wastewater treatment. J. Mater. Chem. 2011, 21, 3664-3671. [CrossRef]

8. Liu, W.; Zhong, W.; Du, Y.W. Magnetic nanoparticles with core/shell structures. J. Nanosci. Nanotechnol. 2008, 8, 2781-2792. [CrossRef]

9. Oliveira, A.A.S.; Tristão, J.C.; Ardisson, J.D.; Dias, A.; Lago, R.M. Production of nanostructured magnetic composites based on $\mathrm{Fe}^{0}$ nuclei coated with carbon nanofibers and nanotubes from red mud waste and ethanol. Appl. Catal. B Environ. 2011, 105, 163-170. [CrossRef]

10. Sosnovik, D.E.; Nahrendorf, M.; Weissleder, R. Magnetic nanoparticles for MR imaging: Agents, techniques and cardiovascular applications. Basic Res. Cardiol. 2008, 103, 122-130. [CrossRef]

11. Wang, X.B.; Zhang, P.; Wang, W.; Lei, X.; Zou, B.; Yang, H. Synthesis, structure and magnetic properties of graphite carbon encapsulated $\mathrm{Fe}_{3} \mathrm{C}$ nanoparticles for applications as adsorbents. RSC Adv. 2015, 5, 27857-27861. [CrossRef]

12. Bystrzejewski, M. Synthesis of carbon-encapsulated iron nanoparticles via solid state reduction of iron oxide nanoparticles. J. Solid State Chem. 2011, 184, 1492-1498. [CrossRef]

13. Zhu, K.R.; Chen, C.L.; Xu, M.W.C.; Chen, K.; Tan, X.L.; Wakeel, M.; Alharbi, N.S. In situ carbothermal reduction synthesis of Fe nanocrystals embedded into $\mathrm{N}$-doped carbon nanospheres for highly efficient $\mathrm{U}$ (VI) adsorption and reduction. Chem. Eng. J. 2018, 331, 395-405. [CrossRef]

14. Park, J.B.; Jeong, S.H.; Jeong, M.S.; Kim, J.Y.; Cho, B.K. Synthesis of carbon-encapsulated magnetic nanoparticles by pulsed laser irradiation of solution. Carbon 2008, 46, 1369-1377. [CrossRef]

15. Jian, N.W.; Li, Z.; Fan, Y.; Zhao, M.S. Synthesis of carbon encapsulated magnetic nanoparticles with giant coercivity by a spray pyrolysis approach. J. Phys. Chem. B 2007, 111, 2119-2124. [CrossRef]

16. Li, H.P.; Zhao, N.Q.; He, C.N.; Shi, C.S.; Du, X.W.; Li, J.J. Fabrication of carbon-coated cobalt nanoparticles by the catalytic method. J. Alloy. Compd. 2008, 458, 130-133. [CrossRef]

17. Manawi, Y.M.; Samara, A.; Al-Ansari, T.; Atieh, M.A. A review of carbon nanomaterials' synthesis via the chemical vapor deposition (CVD) method. Materials 2018, 11, 822. [CrossRef]

18. Liu, X.G.; Wang, C.J.; Yang, Y.Z.; Guo, X.M.; Wen, H.R.; Xu, B.S. Synthesis of nano onion-like fullerenes by using $\mathrm{Fe} / \mathrm{Al}_{2} \mathrm{O}_{3}$ as catalyst by chemical vapor deposition. Chin. Sci. Bull. 2009, 54, 137-141. [CrossRef]

19. Zhang, C.G.; Li, J.J.; Liu, E.Z.; He, C.N.; Shi, C.S.; Du, X.W.; Hauge, R.H.; Zhao, N.Q. Synthesis of hollow carbon nano-onions and their use for electrochemical hydrogen storage. Carbon 2012, 50, 3513-3521. [CrossRef]

20. Li, H.P.; Li, Y.; Zhang, Y.G.; Liang, C.Y.; Wang, H.S.; Li, B.; Adair, D.; Bakenov, Z. Fabrication and properties of carbon-encapsulated cobalt nanoparticles over $\mathrm{NaCl}$ by CVD. Nanoscale Res. Lett. 2016, 11, 432. [CrossRef]

21. Ng, T.B.; Liu, W.K. Toxic effect of heavy metals on cells isolated from the rat adrenal and testis. In Vitro Cell. Dev. Biol. 1990, 26, 24-28. [CrossRef]

22. Brunauer, S.; Emmett, P.H.; Teller, E. Adsorption of gases in multimolecular layers. J. Am. Chem. Soc. 1938, 60, 309-319. [CrossRef]

23. Barrett, E.P.; Joyner, L.G.; Halenda, P.P. The determination of pore volume and area distributions in porous substances. I. Computations from nitrogen isotherms. J. Am. Chem. Soc. 1951, 73, 373-380. [CrossRef]

24. Ağaoğulları, D.; Madsen, S.J.; Ögüt, B.; Koh, A.L.; Sinclair, R. Synthesis and characterization of graphite-encapsulated iron nanoparticles from ball milling-assisted low-pressure chemical vapor deposition. Carbon 2017, 124, 170-179. [CrossRef]

25. Liu, J.; Yu, B.W.; Zhang, Q.K.; Hou, L.Z.; Huang, Q.L.; Song, C.R.; Wang, S.L.; Wu, Y.Q.; He, Y.H.; Zou, J.; et al. Synthesis and magnetic properties of $\mathrm{Fe}_{3} \mathrm{C}-\mathrm{C}$ core-shell nanoparticles. Nanotechnology 2015, 26, 085601. [CrossRef]

26. Ermakova, M.A.; Ermakov, D.Y.; Chuvilin, A.L.; Kuvshinov, G.G. Decomposition of methane over iron catalysts at the range of moderate temperatures: The influence of structure of the catalytic systems and the reaction conditions on the yield of carbon and morphology of carbon filaments. J. Catal. 2001, 201, 183-197. [CrossRef]

27. He, C.N.; Zhao, N.Q.; Du, X.W.; Shi, C.S.; Ding, J.; Li, J.J.; Li, Y.D. Low-temperature synthesis of carbon onions by chemical vapor deposition using a nickel catalyst supported on aluminum. Scr. Mater. 2006, 54, 689-693. [CrossRef] 
28. He, C.N.; Du, X.W.; Ding, J.; Shi, C.S.; Li, J.J.; Zhao, N.Q.; Cui, L. Low-temperature CVD synthesis of carbon-encapsulated magnetic Ni nanoparticles with a narrow distribution of diameters. Carbon 2006, 44, 2330-2333. [CrossRef]

29. Huang, C.W.; Wu, H.C.; Lin, W.H.; Li, Y.Y. Temperature effect on the formation of catalysts for growth of carbon nanofibers. Carbon 2009, 47, 795-803. [CrossRef]

30. Nemanich, R.J.; Solin, S.A. First- and second-order Raman scattering from finite-size crystals of graphite. Phys. Rev. B 1979, 20, 392. [CrossRef]

31. Zhang, S.W.; Zeng, M.Y.; Li, J.X.; Li, J.; Xu, J.Z.; Wang, X.K. Porous magnetic carbon sheets from biomass as an adsorbent for the fast removal of organic pollutants from aqueous solution. J. Mater. Chem. A 2014, 2, 4391-4397. [CrossRef]

32. McCusker, L.B.; Liebau, F.; Engelhardt, G. Nomenclature of structural and compositional characteristics of ordered microporous and mesoporous materials with inorganic hosts: (IUPAC recommendations 2001). Pure Appl. Chem. 2001, 73, 381-394. [CrossRef]

33. Li, C.D.; Lu, J.J.; Li, S.M.; Tong, Y.B.; Ye, B. Synthesis of magnetic microspheres with sodium alginate and activated carbon for removal of methylene blue. Materials 2017, 10, 84. [CrossRef]

34. Liu, D.H.; Guo, Y.; Zhang, L.H.; Li, W.C.; Sun, T.; Lu, A.H. Switchable transport strategy to deposit active $\mathrm{Fe} / \mathrm{Fe}_{3} \mathrm{C}$ cores into hollow microporous carbons for efficient chromium removal. Small 2013, 9, 3852-3857. [CrossRef]

35. Lust, E.; Vaarmets, K.; Nerut, J.; Tallo, I.; Valk, P.; Sepp, S.; Härk, E. Influence of specific surface area and microporosity-mesoporosity of pristine and Pt-nanoclusters modified carbide derived carbon electrodes on the oxygen electroreduction. Electrochim. Acta 2014, 140, 294-303. [CrossRef]

36. Bystrzejewski, M.; Łabędź, O.; Kaszuwara, W.; Huczko, A.; Lange, H. Controlling the diameter and magnetic properties of carbon-encapsulated iron nanoparticles produced by carbon arc discharge. Powder Technol. 2013, 246, 7-15. [CrossRef]

37. Sinclair, R.; Li, H.; Madsen, S.; Dai, H.J. HREM analysis of graphite-encapsulated metallic nanoparticles for possible medical applications. Ultramicroscopy 2013, 134, 167-174. [CrossRef]

38. Liao, Y.P.; Pan, K.; Wang, L.; Pan, Q.J.; Zhou, W.; Miao, X.H.; Jiang, B.J.; Tian, C.G.; Tian, G.H.; Wang, G.F.; et al. Facile synthesis of high-crystallinity graphitic carbon/ $\mathrm{Fe}_{3} \mathrm{C}$ nanocomposites as counter electrodes for high-efficiency dye-sensitized solar cells. ACS Appl. Mater. Inter. 2013, 5, 3663-3670. [CrossRef]

39. He, C.N.; Zhao, N.Q.; Shi, C.S.; Li, J.J.; Li, H.P. Magnetic properties and transmission electron microscopy studies of Ni nanoparticles encapsulated in carbon nanocages and carbon nanotubes. Mater. Res. Bull. 2008, 43, 2260-2265. [CrossRef]

40. Sergiienko, R.; Shibata, E.; Zentaro, A.; Shindo, D.; Nakamura, T.; Qin, G.W. Formation and characterization of graphite-encapsulated cobalt nanoparticles synthesized by electric discharge in an ultrasonic cavitation field of liquid ethanol. Acta Mater. 2007, 55, 3671-3680. [CrossRef]

41. Ogawa, T.; Kura, H.; Takahashi, M. Simultaneous agglomeration of Fe/Au nanoparticles with controllability of magnetic dipole interaction. Scr. Mater. 2011, 64, 1067-1070. [CrossRef]

42. Qiu, J.S.; Li, Q.X.; Wang, Z.Y.; Sun, Y.F.; Zhang, H.Z. CVD synthesis of coal-gas-derived carbon nanotubes and nanocapsules containing magnetic iron carbide and oxide. Carbon 2006, 44, 2565-2568. [CrossRef]

43. Daneshvar, E.; Vazirzadeh, A.; Niazi, A.; Kousha, M.; Naushad, M.; Bhatnagar, A. Desorption of methylene blue dye from brown macroalga: Effects of operating parameters, isotherm study and kinetic modeling. J. Clean. Prod. 2017, 152, 443-453. [CrossRef]

44. Baseri, H.; Tizro, S. Treatment of nickel ions from contaminated water by magnetite based nanocomposite adsorbents: Effects of thermodynamic and kinetic parameters and modeling with Langmuir and Freundlich isotherms. Process Saf. Environ. 2017, 109, 465-477. [CrossRef]

45. Wu, J.; Yu, H.Q. Biosorption of 2, 4-dichlorophenol by immobilized white-rot fungus Phanerochaete chrysosporium from aqueous solutions. Bioresour. Technol. 2007, 98, 253-259. [CrossRef]

46. Xu, L.; Guo, C.; Wang, F.; Zheng, S.; Liu, C.Z. A simple and rapid harvesting method for microalgae by in situ magnetic separation. Bioresour. Technol. 2011, 102, 10047-10051. [CrossRef]

(C) 2019 by the authors. Licensee MDPI, Basel, Switzerland. This article is an open access article distributed under the terms and conditions of the Creative Commons Attribution (CC BY) license (http:/ / creativecommons.org/licenses/by/4.0/). 